\title{
Simultaneous detection of 12 mycotoxins in cereals using RP-HPLC-PDA-FLD with PHRED and a post-column derivatization system.
}

\begin{abstract}
A new method for the simultaneous quantification of 12 mycotoxins was developed and optimized using reverse phase high performance liquid chromatography (RP-HPLC) with a photodiode array (PDA) and fluorescence detector (FLD), a photochemical reactor for enhanced detection (PHRED) and post-column derivatization. The mycotoxins included aflatoxins (AFB1, AFB2, AFG1, and AFG2), ochratoxin A (OTA), zearalenone (ZEA), deoxynivalenol (DON), fumonisins (FB1, FB2, and FB3), T-2 and HT-2 toxins. A double sample extraction with a phosphate-buffered saline solution (PBS) and methanol was used for co-extraction of mycotoxins, and a multifunctional immunoaffinity column was used for cleanup. Optimum conditions for separation of the mycotoxins were obtained to separate 12 mycotoxins in FLD and PDA chromatograms with a high resolution. The method gave recoveries in the range $72-111 \%$ when applied to spiked corn samples. The limits of detection (LOD) were $0.025 \mathrm{ng} / \mathrm{g}$ for AFB1 and AFG1, $0.012 \mathrm{ng} / \mathrm{g}$ for AFB2 and AFG2, $0.2 \mathrm{ng} / \mathrm{g}$ for OTA, $1.5 \mathrm{ng} / \mathrm{g}$ for ZEA, $6.2 \mathrm{ng} / \mathrm{g}$ for FB1, FB3 and HT-2 toxin, $9.4 \mathrm{ng} / \mathrm{g}$ for FB2 and T-2 toxin, and $18.7 \mathrm{ng} / \mathrm{g}$ for DON. In addition, the limits of quantification (LOQ) ranged from $0.04 \mathrm{ng} / \mathrm{g}$ for AFB2 and AFG2 to $62 \mathrm{ng} / \mathrm{g}$ for DON. The method was successfully applied to the determination of these mycotoxins in 45 cereal samples obtained from the Malaysian market. The results indicated that the method can be applied for the multi-mycotoxin determination of cereals.
\end{abstract}

Keyword: Cereals; High-performance liquid chromatography; Mycotoxins. 